\title{
La dama de Bizanci. Un enigma en la nissaga de Jaume I
}

\author{
Ernest Marcos
}

Barcelona, Publicacions de la Universitat de Barcelona, 2013

La lectura de La dama de Bizanci esdevé ja des del primer moment un exercici apassionant. L'obra és un assaig històric que pren per motiu explicar el fet, força sorprenent, que el rei Jaume I d'Aragó i Comte de Barcelona tingués per àvia del cantó matern una veritable princesa de la cort bizantina. Encara que no fos filla de l'emperador Manuel Comnè, tal com li agrada al Conqueridor de fer creure a l'inici de la seva Crònica, Eudòcia Comnena, que aquest era el nom de l'àvia, era una princesa imperial per la sang, filla d' Isaac, germà del mateix emperador. Per aclarir el com i el perquè aquesta núvia, en principi destinada a Ramon Berenguer IV de Provença, germà del comte-rei Alfons I el Trobador, acabà casant-se amb el noble Guillem VIII de Montpeller de categoria inferior a la d'ella, l'autor del llibre emprèn un estudi dels esdeveniments històrics del segle XII a tota la conca del Mediterrani, especialment durant la segona meitat d'aquest segle i els inicis del segle XIII.

Ernest Marcos traça, amb la cura i la precisió de qui a més d'especialista en història bizantina i medieval és també filòleg, un fresc esplèndid, o millor dit, un tapís, ple de detalls, on podem seguir l'entrellat complex dels fets polítics, socials, religiosos, diplomàtics, militars i econòmics que conduïren una núvia grega a esdevenir senyora de Montpeller i emperadriu cantada pels trobadors occitans. La reconstrucció està basada en els testimonis de diversos cronistes i documents contemporanis dels fets, a més de l'obra d'historiadors posteriors i una àmplia bibliografia d'estudiosos actuals. Així mateix l'autor ens fa participar de tant en tant de les seves hipòtesis personals o de la seva opinió sobre la veritat o la versemblança d'allò que ens narra, assenyalant-ho sempre de manera clara. En aquest viatge intricat a través dels camins sovint no massa honestos transitats per reis, senyors i prelats poderosos del segle XII, així com per dames d'alt llinatge però sense capacitat de decidir, l'autor tracta d'illluminar tant com li és possible els paisatges a fi que ens resultin més propers i, per tant, els fets ens siguin més entenedors. Això ho aconsegueix amb diferents estratègies. Una, presentant les accions des dels diferents punts de vista dels agents implicats i tenint en compte els seus costums, la seva religió,el seu afany de poder i la manera d'entendre la política: no és el mateix la cort bizantina i el seu emperador Manuel Comnè, o el comte-rei d'Aragó i els senyors dels casals catalans i occitans, o els interessos de les potències marítimes i comercials italianes, o la visió imperial de Frederic Barba-roja, o les necessitats i ambicions dels Papes, o la situació precària dels reialmes croats de Palestina, o la cobdícia que les riqueses d'Orient podien despertar en els reis anglesos, francesos i normands de Sicília.Una altra estratègia, que recorda la tècnica minuciosa del miniaturista, del teixidor de tapissos o del pintor de frescos, és la de presentar-nos tots els personatges que apareixen amb 
els seus noms propis, per llargs que siguin, i citar els noms de les ciutats, de les esglésies i els dies dels sants en què tingueren lloc els esdeveniments. Tots aquests noms, de sonoritats diferents segons siguin grecs, turcs, germànics, italians, occitans o catalans componen una espècie de simfonia que, lluny de crear confusió, ens ajuda a evocar sigui la cort opulenta i refinada de Bizanci, plena de Teodores, Irenes, Maries, Andrònics, Àngels o Isaacs, sigui els palaus occitans on es movien Ramons, Berenguers, Guillems, Guius, Bertrands, Azalais, Agnès o Comptors, o bé la cort imperial itinerant dels Frederics, Enrics, Christians, Bertes, o els feus papals de Rolando Bandinelli - Alexandre III-, o de Lotario dei Conti dei Segni - Innocenci III-, o els noms francesos dels reis anglesos Enric Plantagenet i Elionor d'Aquitània, o dels Hauteville sicilians, etc. És cert que no acabaríem mai si volguéssim esmentar tot el devessall de noms propis que apareixen a La dama de Bizanci, i que sens dubte són, a més d'una mostra de rigor i de precisió, un important element estilístic.

La història, més aviat trista, d'Eudòcia Comnena, cal inscriure-la en el marc de l'enfrontament èpic que sostingueren l'emperador germànic Frederic Barbaroja i l'emperador bizantí Manuel Comnè durant gairebé trenta anys — des de l'ascensió al tron del primer el 1152 fins a la mort del segon el 1180-, per tal de ser reconeguts com a únic hereu legítim i continuador dels emperadors romans i gaudir així del nom d'emperador universal. En el joc diplomàtic derivat d'aquesta pugna, li semblà bé al basileu bizantí accedir a la petició del comte-rei Alfons I de casar una princesa grega $\mathrm{amb}$ el seu germà el comte de Provença. Però posteriorment el rei català canvià d'opinió a fi de no enemistar-se amb l'emperador Frederic, i la núvia, que ja havia arribat al seu destí, es casà amb el senyor de Montpeller, un fidel aliat del comte-rei. En el contracte matrimonial s'hi inclogué una "clàusula bizantina", que assegurava als fills (o filles, si no hi havia descendència masculina) nascuts d'aquesta unió l'herència de la senyoria de Montpeller. Repudiada anys després per Guillem VIII precisament per no haver tingut un fill mascle, la grega ortodoxa visqué els seus darrers anys reclosa a una abadia benedictina, mentre seguia, de lluny estant, les estacions del viacrucis de la seva única filla, Maria de Montpeller, tan desventurada com ella mateixa. Captiva en una xarxa d'interessos intricats i contradictoris, l'emperadriu Eudòcia fou, com totes les aristòcrates medievals, una peça en el joc diplomàtic de les grans potències, valuosa mentre les circumstàncies n'afavorien la utilització, però perfectament negligible quan les condicions de l'escenari polític canviaven. El sofriment de la bizantina trobà continuació en la dissort de la seva filla Maria, que a les afliccions heretades de la mare hi afegí el rebuig cruel del seu reial espòs.

No obstant, encara que allunyada del palau, Eudòcia no acceptà mai la dissolució del seu matrimoni. El papa Innocenci III acabà donant-li la raó, i ella tingué la satisfacció de veure reconeguda la seva condició d'esposa legítima i, per tant, dels drets successoris de la seva filla, la futura mare del Conqueridor. La 
princesa grega devia tenir en el moment de la seva mort prop de quaranta anys, la major part passats a Occitània, estretament vinculada en la sort i en la desgràcia a la senyoria de Montpeller. Amb molta probabilitat, només recordava remotament Constantinoble. Però, seixanta anys després del seu traspàs, en el pròleg de la Crònica, Jaume I invocava, commogut i agraït, la memòria de l'àvia bizantina a qui devia el fet extraordinari de dur a les seves venes la sang illustre dels Comnens, timbre indubtable de glòria per a la Casa de Barcelona.

A més de la història d'Eudòcia, el llibre ens permet conèixer el destí tràgic de moltes altres dones d'alt llinatge esdevingudes sovint, des de la seva més tendra infància, un instrument de l'afany de poder dels seus parents masculins. És de lloar que Ernest Marcos hagi pres la cura d'incloure en el seu assaig històric totes aquestes dones i hagi sabut mostrar-nos el paper cabdal que tingueren en el teixit dels esdeveniments, de vegades manipulades com a simples peons, però d'altres convertides en agents lúcids que, com Eudòcia Comnena i Maria de Montpeller, saberen preservar, malgrat el sofriment, la pròpia dignitat i el futur dels seus fills.

D.O.I.:

MONTSERRAT JUFRESA

Universitat de Barcelona

\section{Genealogías feministas en el arte español: 1960-2010}

Juan Vicente Aliaga y Patricia Mayayo (eds.)

Madrid, This Side Up, 2013

La publicación Genealogías feministas en el arte español: 1960-2010 está relacionada con la exposición que, con el mismo título, se celebró en el MUSAC (Museo de Arte Contemporáneo de Castilla y León) entre junio de 2012 y febrero de 2013. No se trata, sin embargo, de una publicación con el formato tradicional que acompaña las exposiciones artísticas: no es un catálogo, sino que fue pensada como una extensión de la exposición y pretende recoger, en palabras del entonces director del MUSAC - y propiciador de la exposición- Agustín Pérez Rubio, "el marco conceptual y teórico y gran parte del proyecto expositivo". Se encargaron de su edición los curadores de la exposición, Juan Vicente Aliaga y Patricia Mayayo, ambos con una larga trayectoria tanto de investigación sobre arte y género como de curaduría de proyectos artísticos feministas.

El MUSAC fue - mientras estuvo bajo la dirección de Pérez Rubio- un museo comprometido con una programación en la que estaban muy presentes cuestiones de género y de diferencia sexual. Genealogías feministas visibilizó, en un esfuerzo magnífico, una selección de obras femeninas y feministas realizadas en el estado español desde la década de 1960 hasta la actualidad, estructurada 